DOI: $10.14451 / 1.174 .7$

\title{
РОССИЙСКИЙ ПРОТЕКЦИОНИЗМ ДОКАПИТАЛИСТИЧЕСКОЙ ЭПОХИ
}

\author{
(C) 2019 Возова Наталья Александровна
}

аспирантка кафедры Политической экономии и истории экономической науки Российский экономический университет имени Г.В. Плеханова, Россия, Москва

E-mail: nvozova@yandex.ru

Статья посвящена оценке элементов протекционизма в политике правителей России XVIIXVIII веков. Установлено, что расхождение векторов российской и европейской практик и дискурсов было обусловлено глубокими структурными факторами. Показано, что российская модернизация, являвшаяся результатом государственной инициативы, осуществлялась не рыночными методами, а иногда, напротив, вела к усилению внеэкономической эксплуатации основной массы населения. В условиях отсутствия полноценного рынка труда, полноценного потребительского спроса нарождающаяся рыночно неадаптированная российская промышленность не могла развиваться вне протекционистской опеки правительства. Выявлено, что российская модернизация, постепенно продуцирующая индустриальный порядок, не вела к его либерализации. Именно эта особенность национального модернизационного процесса, несмотря на проникновение в Россию либеральных взглядов европейцев, определяла экономические практики и теоретические представления, которые конструктивно использовали позитивный потенциал протекционизма.

Ключевые слова: мыслители петровской эпохи, протекционизм, внешняя торговля, самоуправление, национальный интерес, таможенные пошлины, отечественная промышленность, торговый баланс.

Идеи протекционизма как комплекса взглядов и практик, отражающих потребность в защите национальной экономики, оказались востребованными в отечественном дискурсе с XVII века, когда Россия, следуя за другими развитыми странами, приступила к построению современного общества.

Одним из первых политических деятелей, экономистов, обративших внимание на необходимость модернизации общественного хозяйства, стал А.Л. Ордин-Нащокин, возглавлявший посольский приказ и, как никто другой осознававший потребность в экономическом развитии российского государства.

Будучи дальновидным политиком, А.Л. Ордин-Нащокин направлял усилия внешнеполитического ведомства на развитие торговли с Персией, Средней Азией, Хивой и Бухарой, при этом все же определяя в качестве главного внешнеполитического приоритета продвижение России на Балтийское море, открывавшее большие возможности «для русской промышленности и казны царя» [1].

Полагая основным «пороком» государственного управления первенство фискальной политики над целями «народнохозяйственными», замечательный деятель эпохи первых Романовых считал главной его целью развитие промыш- ленности и торговли, чем по праву снискал себе статус «первого политико-эконома на Руси». Будучи воеводой Пскова, он решился осуществить проект городского самоуправления, заимствованный из опыта стран Западной Европы, что позволило высвободить предприимчивых «промышленников» из-под «гнета приказной администрации».

По инициативе вновь прибывшего воеводы было принято положение из 17 статей, важнейшие из которых регламентировали общественное управление городом и внешней торговлей. Из посадского общества избирались на три года 15 человек, которые поочередно в земской избе ведали городскими делами: питейным, таможенным сбором и иностранной торговлей.

Основными препятствиями в развитии внешней торговли А.Л. Ордин-Нащокин считал «недостаток капиталов, взаимное недоверие и отсутствие удобного кредита». На устранение этих недостатков и были направлены статьи положения, регулирующие внешнюю торговлю. Малосостоятельным торговцам предписывалось распределяться «по свойству и знакомству» между богатыми купцами. Земской избе было поручено выдавать им на расширение торгового дела ссуды, «употребляемые на закупку русских вывозных товаров». В свою очередь для облегче- 
ния торговли иноземных купцов были учреждены под Псковом две двухнедельные ярмарки «с беспошлинным торгом» (с 6 по 20 января и с 9 по 23 мая).

Став главой Посольского приказа, приобретенный в Пскове опыт А.Л. Ордин-Нащокин попытался распространить в других «торгующих» городах страны. Вершиной мысли и практической деятельности «московского государственного человека XVII века», как его назвал B.О. Ключевский стал принятый по его инициативе в 1667 году Новоторговый устав, носивший явно выраженный протекционистский характер. Документ содержал введение, 9 статей и приложение, специально регламентирующее порядок торговли иностранцев. В Уставе торговли (так именовалось приложение) устанавливались место и время торговли (на ярмарках в приграничных городах) и перечень допускаемых к торговле в России товаров. Иностранным купцам запрещалось брать подряды, вести розничную торговлю с тем, чтобы не создавать конкуренцию отечественным купцам; ограничивался привоз ими некоторых дорогостоящих товаров: вин, сахара, леденцов, жемчуга, драгоценных камней, украшений. В свою очередь те из иностранцев, которые закупали отечественные продукты за золото и ефимки, освобождались от уплаты пошлин. Другие иноземные купцы, напротив, обязывались платить пошлину золотом, что способствовало притоку в казну драгоценных металлов.

Значительный вклад в развитии общественно-политической мысли России сыграли труды хорватского мыслителя Ю. Крижанича (16181683), прибывшего в Москву в 1659 году. Его экономические взгляды вошли в отечественную антологию благодаря публикации издателем П. Безсоновым произведения под названием «Русское государство в половине XVII века» [2].

В первом разделе своей книги «О благе» Ю. Крижанич развернул набор мыслей о средствах и способах, «коими собирается и обогащается государственная казна». Среди таковых автор называл ложными: алхимию, подделку драгоценных металлов, «неумеренность и алчность налогов и пошлин», «допущение иностранных торговцев». Среди свойств и целей «истинных и прибыльных путей государственного обогащения» Ю. Крижанич называл торговлю, которая, по его мнению, должна находиться «в руках государства». При этом говоря о роли государства, хорватский мыслитель имел в виду прежде всего его организующее начало: определение направлений внешней торговли, мест для проведения «торжищ», создание системы вольных пристаней, ежегодных выставок, путей сообщений, почт, охранения привозимых товаров, единых мер и весов, препятствование в засилии посредников, монополистов, прасолов, иностранных торговцев, учреждение «ссуд без роста и с ростом», меновых контор, банков, торговой полиции и т.д.

Учитывая отсутствие опыта международной торговли России, Ю. Крижанич подчеркивал пагубность неэквивалентной торговли с иностранными купцами, которую мыслитель относил к первейшей причине «земли разорения».

Для подтверждения своих опасений Ю. Крижанич приводил пример, когда европейские купцы вывозили из России ценную «ясачную пушнину», купленную «за безделицу», а затем ввозили в страну меховые изделия и продавали их за серебро.

Безусловным злом Ю. Крижанич считал ввоз иностранцами предметов роскоши. «Неумеренные роскоши,- писал он,- приносят телу болезнь: неумеренное благо порождает нищету» [2].

В рассуждениях Ю. Крижанича содержится указание по поводу тех обязанностей государства, которые необходимо реализовать для продвижения национальных интересов во внешней торговле. К таковым интеллектуал относил установление «сметы товаров», дабы предотвратить закупку иностранцами отечественной продукции по низким ценам, объема и качества импорта («в коих нет избытка»), организацию транзитной торговли («А сукна и всякие товары немецкие будут проходить через наши руки: на Сибирь, к Бухарцам и к Индийцам: на Астрахань к Персам: на Азов к Туркам: на Путивль к Черкасам и к Воложанам. И напротив, тех народов товары будут приходить к нам, и через наши руки к Немцам, к Ляхам и к Литве»2), обеспечение безопасности торгового трафика, учреждение регламента, согласно которому иноземные купцы могли оптом продавать свой товар «токмо в двух, трех местах в державе» торговым «оправщикам», действующим под надзором царевых думников и надзорников, которым вменялся контроль над ценами («отправники да продают всем одинаковою указною ценой»), установление твердой системы мер и весов («весы и меры одинаковы»), для чего Ю. Крижанич предлагал «во всяком 
большом граде иметь мерников» и царских торговцев, последним помимо надзора за сбором таможенных пошлин должно вменяться «знать о всячине, где и что продать: кто чем торгует: и что в граду есть, и чего нет. И да будет повинен, за мьсто, людям пытающим поведать, где чего искать купить, либо продать». Замечательно, что в проекте Ю. Крижанича царские торговцы наделялись правом покупать и продавать товар дробно и оптом для регулирования внутренних цен.

Второй раздел книги «О ремесле» посвящен, согласно названию, народному рукоделию, мастерство и качество которого, по мнению Ю. Крижанича, только нарождалось в стране. С целью его преумножения он считал необходимым перевести на русский язык книги о промышленном производстве в других государствах («что было бы полезно и годно знанию»).

Забота государя в видении замечательного хорвата заключалась в создании условий, при которых отечественные промышленники перерабатывали бы «из иных стран к нам привозимого изобилия сырово (сырья - aвт.) и несделанного: якоже железо добро, медь, олово, красила, волокна, бумагу» и, напротив, препятствовании вывозу сырья.

Патриотично настроенный Ю. Крижанич настаивал на том, что государство должно переломить ситуацию, когда вывозимое в больших масштабах сырье возвращается в Россию готовыми изделиями, прибавив в цене в десятки раз. Он полагал необходимым развитие в стране ремесел, которые, по его мнению, должны приумножить ее богатства, посредством политики поощрения промышленного производства.

Таким образом, уже в XVII в., на заре российской модернизации, протекционизм как мировоззренческий феномен вполне актуализировался в общественно-политической мысли и в силу «догоняющего» характера последней приобретал особенно радикальные черты. Национальная специфика протекционизма проявлялась в избыточной государственной опеке за развитием ремесла и торговли, что объяснялось прежде всего патерналистским характером российской модернизации, осуществляемой «сверху» государством и в интересах государства.

Еще более последовательно протекционизм государственной экономической политики проявился в петровскую эпоху. Революционные методы модернизации страны, присущие поли- тике Петра I, в условиях дефицита ресурсов особенно востребовали протекционистские идеи и практики.

С целью поощрения отечественного производства таможенным регламентом 1724 г. были введены высокие ввозные пошлины на иностранный товар, доходившие до 37 1/2 \% от цены [3]. Для забот об отечественной промышленности был учрежден специальный государственный орган - мануфактур и берг-коллегия. Приоритет государственных интересов и патерналистский характер промышленной политики Петра I хорошо просматривается в методах «насаждения» крупного фабричного производства. Так для создания предприятий, выпускающих продукцию импортозамещения, практиковалось создание «кумпанств». Например, кумпанство «вельмож: Шафирова, Толстого и Меньшикова начало производство шелка, бархата и др. материала» [3].

Специальным трудом, включавшим значительный круг экономической проблематики петровской эпохи, стала книга И.Т. Посошкова (1652-1726 гг.) «Книга о скудости и богатстве» [4]. Его сочинение отличает глубокое знание хозяйственной реальности страны, так как автор происходил из семьи ремесленников серебряного дела, входившей в число непашенных дворцовых крестьян.

Как и зарубежные меркантилисты, И.Т. Посошков считал необходимым для обеспечения богатства страны приток денег из-за ее пределов и сокращение вывоза их за границу. Для этого он полагал необходимым «развивать внешнюю торговлю и собственную промышленность как для покрытия внутреннего спроса, так и в особенности для производства товаров» [4] на экспорт. Средство устранения оттока денег за границу он видел в ограничении привоза иностранных товаров и особенно предметов роскоши.

Роль государства в развитии экономики страны по И.Т. Посошкову сводилась к «принудительным мерам» насаждения промышленных предприятий, организации кредита купечеству и объединению их в компании.

По мнению И.Т. Посошкова, импорт товара препятствовал рождению отечественных промышленных отраслей. Например, в отношении стеклянного производства он замечал: «Нам если заводов пять, шесть построить, то мы все их государство стеклянной посудой наполнить 
можем» [4].

По поводу роли государства в индустриализации страны И.Т. Посошков указывал на необходимость постройки фабрично-заводских предприятий «на казенный счет» и затем передачи их в частные руки на основе оброчных отношений. Кроме того, согласно его проекта, государство должно было выдавать ссуды «маломочным» хозяевам для постройки промышленных заведений и приобретения оборудования. При этом, по его мнению, государственный кредит на нужды промышленности не должен был выдаваться более чем под 6\% годовых [4].

Несмотря на то, что в книге И.Т. Посошкова отсутствует четкая формулировка об активном торговом балансе, отдельные его замечания достаточно ясно передают смысл торговой политики, основанной на равенстве ввоза и вывоза. Если иноземные купцы,- писал он,- не будут согласны с высокими ценами на русские товары и, «оставя торг, поедут за море без наших товаров, то и свои они товары, с коими приехали, повезли бы все с собою назад». Таким образом, очевидно, что автор «Книги о скудости и богатстве» имел в виду необходимость баланса между ввозом и вывозом товара во внешнеэкономических отношениях.

Краткий обзор протекционистских взглядов мыслителей петровской эпохи дает основание отметить еще одну его характерную черту, обусловленную национальной особенностью модернизационного процесса. Осуществляемая «сверху» политика индустриализации страны не предполагала сколько-нибудь основательного периода первоначального накопления капитала; агрегирование материальных ресурсов в руках государства, являвшегося главным инициатором модернизации, обеспечивалось редистрибутивным характером распределения национального богатства. В силу такой специфики Россия не нуждалась в собирании ресурсов, осуществляемом на Западе за счет ограбления территорий, освоенных в ходе великих географических открытий и набиравшей в то время масштаб внешней торговли.

Одним словом, оценивая протекционистскую политику Петра I, следует заметить, что в условиях, когда торговый режим и собственно инициатива развития промышленного производства находились в руках одного персонифицированного центра регулирования, было трудно соблюсти баланс интересов нарождающейся промышленности и свободы внешнеторгового оборота. Многие меры петровской администрации, имеющие целью развитие индустрии и материальной состоятельности страны, оборачивались прямо противоположными результатами. Уже в 1731 г. был принят новый таможенный устав, понизивший ввозные пошлины на половину и больше. Для поддержки отечественной промышленности были предоставлены «разные преимущества - беспошлинный отпуск большей части изделий и беспошлинная покупка материалов, а также дозволение покупки деревень к фабрикам и заводам» [5].

Во время царствия Елизаветы Петровны, пытавшейся следовать заветам отца, деструктивное содержание «промышленного протекционизма» усилилось вследствие предоставления откупов и монополий целым отраслям производства: например, сусальной, волочильной, кружевной, шляпной, обойной, красочной, мозаичной [5].

Эпоха Екатерины Великой знаменовалась ростом внимания общественности к проблемам экономического развития. Специальные записки по этим проблемам подавали М.В. Ломоносов, В. Татищев, князь Щербатов, князь Вяземский и др. В наказах депутатам, избранным в Комиссию для составления Уложения, практически повсеместно содержались положения относительно торговли и фабричного производства.

Свой «Наказ о составлении проекта нового Уложения» предложила и императрица, в котором высказала свои соображения относительно хозяйственного развития страны. Глава XIII этого опуса была целиком посвящена «рукоделию и торговле».

Лейтмотивом екатерининского наказа проходила логическая линия, явно корреспондирующаяся с интересами помещиков, в поддержке которых она явно нуждалась на первом этапе своего правления. Уже в первом пункте раздела, посвященного промышленности и торговле, говорилось, что «не может быть там ни искусное рукоделие, ни твердо основанная торговля, где земледелие в уничижении или нерачительно производится» [6].

Вполне соответствовало интересам крупных товарных землевладений и положение наказа императрицы о свободе внешнеторгового обмена. «Торговля оттуда удаляется,- писала Екатерина II, - где ей делают притеснение, и водворяется там, где ее спокойствия не нарушают» [6]. Однако, высказавшись в пользу свободы тор- 
говли, автор наказа была вынуждена вернуться к доминирующему на протяжении всей истории интересу государства, который, несмотря на «просвещенный абсолютизм» правительницы, оказывался выше других интересов.

В дополнении к Большому наказу Екатерина II ясно сформулировала положение о необходимости поддержания активного торгового баланса. «Торговля, хорошо учрежденная и рачительно отправляемая, все животворит, все поддерживает,- писала она,- если она внешняя, и баланс, то есть перевес оной для нас выгоден» [6].

Развитию отечественной промышленности и торговли способствовал курс Екатерины II на упразднение предоставляемых в елизаветинскую эпоху откупов и монополий. Упразднялась Халитовская компания, монополизирующая черноморский торг, товарищество Шемякина, сосредоточивающего торговлю с Персией, монополии смоляного торга, ситцевых фабрик, рафинадных заводов, сальных Беломорских предприятий, Каспийских тюленевых промыслов и т.д. Ликвидировались, в том числе, многие казенные мануфактуры. Например, ревенная. Отменялся запрет на вывоз за границу узкого крестьянского холста, хряща, соломы и скота в живом виде [6].

Важным не только с точки зрения практической, но и теоретической, в оценке протекционистских мер правительства, было предложение Комиссии о коммерции, созданной для пересмотра действующего таможенного устава, заключающееся в необходимости пересмотра каждые пять лет (в зависимости от успехов национальной промышленности и изменений в соотношении от состояния торгового баланса) таможенных пошлин на импорт и экспорт.

Важные теоретические вопросы относительно внешнеэкономических отношений высказал член Комиссии о коммерции граф С.Ф. Миних. В своей записке относительно «Рассуждений господина генерал-прокурора о направлении баланса российской торговли» он замечал, что международный торговый обмен может осуществляться только на взаимной основе. «Россия, желая продолжать и увеличивать свой выпуск, не может без того обойтись, чтобы не принимать взамен разных произведений и товаров, с какими приезжая к ней знакомые народы стараться будут оные у нее сбывать» [7].

Заградительная политика государства, по мнению С.Ф. Миниха, должна строиться на основе баланса интересов отечественной промышленности, пополнения казны за счет пошлин и сборов, потребителей из числа состоятельной части населения и рядовых граждан. В этой связи абсолютные запреты в его представлении являлись нежелательными и крайними мерами.

Другой член Комиссии, князь М.М. Щербатов, также высказал свое мнение «по тому же предмету» [8]. Говоря о свободе торговли, М.М. Щербатов полагал, что «под именем вольности (он не допускает - авт.) чтобы было дано такое самовластие каждому торгующему, чтоб он ни мало не соображаясь с общей пользою Государства» [8]. В обязанности государства, в понимании М.М. Щербатова, входило устранение «всех утеснений» торговли, организация кредита для купцов, «предохранение от всякого рода монополий», предоставление режима благоприятствования иностранным купцам, ликвидация проволочек в таможенной службе. Также как С.Ф. Миних, он говорил о необходимости сбалансированной внешнеэкономической политикИ.

Имея в виду необходимость поддержания активного торгового баланса, М.М. Щербатов считал, «что вывоз товаров есть самая лучшая прибыль для нации; что прибыльнее выделанные товары, нежели невыделанные отпускать, и следственно столь же полезно побудить ввоз сырых материй в Государство, дабы в оном они обработаны были» [8].

Во избежание несоответствия действующих ввозных и вывозных тарифов, как и оговаривалось ранее именным указом от 27 сентября 1782 г., вводились изменения в «общий тариф для всех портов и пограничных таможен». До 20\% был уменьшен средний размер пошлин на сырые продукты, необходимые для российской промышленности, умеренными пошлинами облагались ввозимые полуфабрикаты.

Для расширения масштабов товарного транзита новым тарифом предусматривались минимальные пошлины на товары иностранцев, предназначенные для перепродажи за границу. Высокой оставалась пошлина на предметы роскоши (но не более 20\%). Исключения составляли предметы, составляющие художественную ценность. Совершенно освобождались от пошлины материалы и снадобья для изготовления лекарств.

Таким образом, начатый курс на определе- 
ние баланса интересов, сочетание мер, направленных на развитие национальной экономики и внешней торговли, продолжился на всем протяжении екатерининского правления. И если в Европе, с утверждением экономического либерализма все больший вес приобретала установ- ка классиков политэкономии о безальтернативности фритредерства, то национальная «почва» создавала условия для направления экономической мысли в другое русло, русло поиска оптимального сочетания протекционизма с свободой торговли.

\section{Библиографический список}

1. Ключевский В.О. Ордин-Нащокин А.Л. Московский государственный человек XVII в.// Научное слово. Кн. Ш. M. 1904. C. 125

2. Крижанич Ю. Русское государство в половине XVII века. Рукопись времен царя Алексея Михайловича. М. 1859.

3. Богословский M.M. Российский XVIII век. Книга первая. М.: Интелвак. 2008. С. 152.

4. Посошков И. Т. Книга о скудости и богатстве. М.: Государственное социально-экономическое издательство. 1937.

5. Ладыженский К.Н. История русского таможенного тарифа. М.; Челябинск: Социум. 2016. С. 78

6. Екатерина II. О величии России. М.: Эксмо. 2006. С. 114.

7. Миних С.Ф. Примечания тайного действительного советника графа С.Ф. Миниха на некоторые пункты, находящиеся в рассуждении господина генерал-прокурора о направлении баланса российской торговли//Приложение IV. Лодыженский К.Н. Указ. Соч. с. 287-293.

8. Щербатов М.М. Мнение члена Комиссии о коммерции князя Щербатова по тому же предмету // приложение V. Ладыженский К. Н. Указ. Соч. С. 294-310. 